\title{
Enhancement of the Dissolution of Nutrient Elements from Steelmaking Slag into Seawater by Gluconic Acid
}

\author{
Xiaorui Zhang • Hiroyuki Matsuura • \\ Fumitaka Tsukihashi
}

Published online: 21 March 2015

(C) The Minerals, Metals \& Materials Society (TMS) 2015

\begin{abstract}
Steelmaking slag has been buried in coast to provide nutrient elements, especially iron, into seawater for the seaweeds' growth. However, the solubility of iron is extremely low under the oxic seawater conditions. In order to stabilize soluble iron which is dissolved from steelmaking slag into seawater, the addition of gluconic acid was investigated in the present study. By using two kinds of synthesized steelmaking slag with different $\mathrm{CaO} / \mathrm{SiO}_{2}$ ratios, the effect of gluconic acid on the dissolution behavior of various elements into seawater, while varying the concentration of gluconic acid and $\mathrm{pH}$, was studied. The dissolution of $\mathrm{Ca}, \mathrm{Si}, \mathrm{P}$, and $\mathrm{Fe}$ was greatly enhanced by the addition of gluconic acid and their concentration increased for increasing gluconic acid concentration. The dissolution mechanisms of each element were discussed using their stability diagrams and the dissolution reactions.
\end{abstract}

Keywords Recycling $\cdot$ Steelmaking slag $\cdot$ Coastal environment · Gluconic acid · Seawater · Dissolution behavior

\footnotetext{
X. Zhang $\cdot$ H. Matsuura $(\bowtie) \cdot F$. Tsukihashi

Department of Advanced Materials Science, Graduate School of Frontier Sciences, The University of Tokyo, 5-1-5-501

Kashiwanoha, Kashiwa, Chiba 277-8561, Japan

e-mail: matsuura@k.u-tokyo.ac.jp

F. Tsukihashi

e-mail: tukihasi@k.u-tokyo.ac.jp

Present Address:

$X$. Zhang

Graduate School of Pure and Applied Sciences, University of

Tsukuba, 1-1-1 Tennodai, Tsukuba, Ibaraki 305-8573, Japan

e-mail: xr_zhang@ims.tsukuba.ac.jp
}

\section{Introduction}

Utilization of steelmaking slag is indispensable for sustainable growth of the steelmaking industry. Steelmaking companies are now seeking new technologies to reduce the amount of steelmaking slag and meet the demand of transforming the slag into a valuable resource. It has been reported by Nakamura et al. [1] that phytoplankton grows positively in cultures with the addition of steelmaking slag, which indicates that steelmaking slag is an effective solution to sea desertification. The latter is also called ISOYAKE or barren grounds along the coastal areas and has been identified as a serious environmental problem not only in Japan but also all over the world. Many measures are used for recovering the now extinct seaweed beds: one of the feasible long-term candidates is steelmaking slag because of its reasonable cost, sufficient quantity, adequate mineral concentration, and the nature of its ionic structure $[2,3]$.

Among the bioactive trace metals, iron is an essential micronutrient element for the multiplication of phytoplankton [1]. Futatsuka et al. [2, 4], Arita et al. [5], and Sugie and Taniguchi $[6,7]$ have confirmed that nutrient elements such as $\mathrm{Fe}, \mathrm{Si}$, and $\mathrm{P}$ can dissolve from steelmaking slag into seawater. However, in oxic seawater, the solubility of iron is extremely low at the normal $\mathrm{pH}$ range of seawater [5-9]. Hence, it is necessary to adopt an efficient way to stabilize soluble $\mathrm{Fe}$ in seawater.

Hydroxycarboxylic acids such as sugar acids are generally released from phytoplankton. As one kind of sugar acid, gluconic acid $\left(\mathrm{HGH}_{4}\right)$ is biologically quite important in living organisms [8]. High concentration of gluconic acid $(0.7-0.8 \mu \mathrm{M})$ was detected in surface seawater during spring bloom in Funka Bay (Japan) coincident with the elevated dissolved Fe(II) $[8,10,11]$. Therefore, it is of great value to investigate the enhancement effect of 
gluconic acid on the dissolution of the elements from steelmaking slag into seawater.

In the present study, the dissolution behavior of $\mathrm{Ca}, \mathrm{Si}$, $\mathrm{P}$, and $\mathrm{Fe}$ from steelmaking slag into seawater was investigated in laboratory-scale experiments, while varying the concentration of gluconic acid and $\mathrm{pH}$. The dissolution mechanisms of the elements were also clarified by using the solubility diagrams in seawater and the potential-pH diagram of iron-water system. Moreover, the mineralogical phases of steelmaking slags before and after shaking experiments were investigated by X-ray diffraction (XRD).

\section{Experimental}

\section{Materials}

Two kinds of slags were examined in the present study and are identical to those used in the previous work [3]; the particle size was under $150 \mu \mathrm{m}$. The slags were prepared by melting a mixture of produced $\mathrm{CaO}$ and $\mathrm{FeO}$, and reagent grade $\mathrm{SiO}_{2}$ and $\mathrm{Ca}_{3}\left(\mathrm{PO}_{4}\right)_{2} \cdot x \mathrm{H}_{2} \mathrm{O}$, at $1723 \mathrm{~K}$ for $50 \mathrm{~min}$, under Ar flow of $1 \mathrm{~L} / \mathrm{min}$, and quenching on a steel plate by jetting Ar gas. Their compositions are shown in Table 1. Under the synthesis conditions, slag S-1 was completely melted, as predicted in the $\mathrm{CaO}-\mathrm{SiO}_{2}-\mathrm{FeO}_{x}$ ternary phase diagram [12], while slag S-2 was partly melted because of its high liquidus temperature.

The phases of slags S-1 and S-2 were characterized by powder X-ray diffraction (XRD: M18XHF, Mac Science,

Table 1 Compositions of synthesized slags (mass \%)

\begin{tabular}{llllll}
\hline slag & $\mathrm{FeO}$ & $\mathrm{CaO}$ & $\mathrm{SiO}_{2}$ & $\mathrm{P}_{2} \mathrm{O}_{5}$ & $\mathrm{CaO} / \mathrm{SiO}_{2}$ \\
\hline $\mathrm{S}-1$ & 30.0 & 33.8 & 33.7 & 2.5 & 1.0 \\
$\mathrm{~S}-2$ & 30.0 & 45.0 & 22.5 & 2.5 & 2.0 \\
\hline
\end{tabular}

Japan) with a $\mathrm{Cu}-\mathrm{K} \alpha$ radiation source $(\lambda=1.5406 \AA)$ at $40 \mathrm{kV}$ and $200 \mathrm{~mA}$ over a range between $20^{\circ}$ and $80^{\circ}$. Figure 1 shows XRD patterns of the synthesized slags S-1 and S-2. XRD patterns revealed that slag S-1 was composed of $\mathrm{CaO} \cdot \mathrm{FeO} \cdot \mathrm{SiO}_{2}$ phase, and slag S-2 was composed of $2 \mathrm{CaO} \cdot \mathrm{SiO}_{2}$ phase and $\mathrm{FeO}$ phase. The phases detected by XRD analysis were consistent with those predicted by the $\mathrm{CaO}-\mathrm{SiO}_{2}-\mathrm{FeO}_{x}$ ternary system.

Artificial seawater was made by dissolving a specific amount of artificial seawater raw materials ("Aquamarine"supplied by BizScience company, Japan) into $20 \mathrm{~L}$ distilled water and adjusting $\mathrm{pH}$ to around 8.2 by adding $0.13 \mathrm{~mol} / \mathrm{L} \mathrm{NaOH}$ solution. Its composition is shown in Table 2.

The $0.12,0.25$, or $0.50 \mathrm{~g} / \mathrm{L}$ gluconic acid-seawater solution was prepared in advance before each experiment. First, the $\mathrm{pH}$ of $50 \%$ gluconic acid (analytic reagent grade, Wako Pure Chemical Industries, Ltd., from 47.0 to 53.0 mass $\%$, density: $1.24 \mathrm{~g} / \mathrm{cm}^{3}$ ) was adjusted to 8.3 by $\mathrm{NaOH}$ solution, and then this gluconic acid was diluted 100 times by seawater to prepare the solution with $6.2 \mathrm{~g} / \mathrm{L}$ and $\mathrm{pH}$ of 7.74. Subsequently, $0.12,0.25$, or $0.50 \mathrm{~g} / \mathrm{L}$ gluconic acidseawater solution was synthesized and their final $\mathrm{pH}$ values were $7.60,7.47$, and 7.45 , respectively.

\section{Shaking Procedure}

The shaking experiments were conducted in batches, in the same manner as that of the previous study [3]. The oscillation speed was 160 cycles/min with an amplitude of $20 \pm 5 \mathrm{~mm}$, and the shaking time varied from 1 to $96 \mathrm{~h}$ (4 days). One gram of slag was added into $100 \mathrm{~mL}$ of artificial seawater-gluconic acid solution in a $250 \mathrm{~mL}$ of polyethylene bottle. The shaking experiments of $1 \mathrm{~g}$ slag/ $100 \mathrm{~mL}$ seawater or $100 \mathrm{~mL}$ of seawater without slag were also conducted for comparison. After shaking, the $\mathrm{pH}$ and oxidation-reduction potential (ORP) of the shaking solution were measured immediately by a $\mathrm{pH}$ meter (IM-55G
Fig. 1 XRD patterns of synthesized slags $\mathrm{S}-1$ and $\mathrm{S}-2$
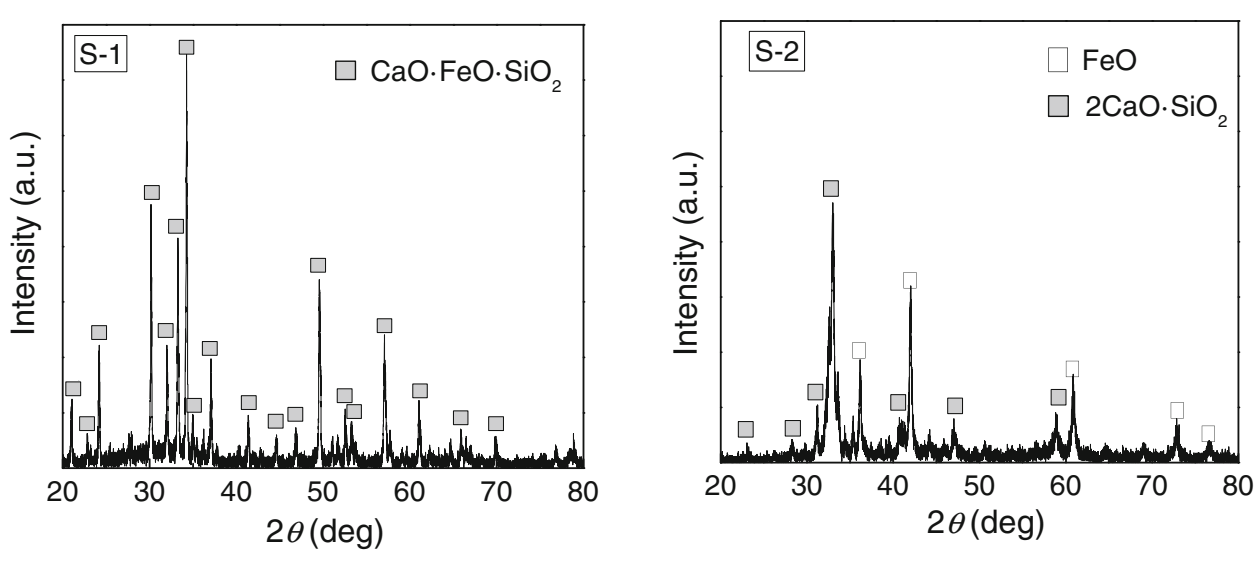
with GST 5731C probe, DKK-TOA Corp.) and an ORP meter (HM-25R with PS-5111C probe, DKK-TOA Corp.). The reference electrode of the ORP probe is $\mathrm{Ag} / \mathrm{AgCl}$, and thus ORP values shown below are those after conversion against the standard hydrogen electrode. Subsequently, the solution was filtrated with a $0.45 \mu \mathrm{m}$ Millipore membrane filter. The concentrations of $\mathrm{Ca}, \mathrm{Mg}$, and $\mathrm{Si}$ were measured by an inductively coupled plasma optical emission spectrometer (ICP-OES, Seiko Instruments Inc., SPS7800 Plasma Spectrometer), and the concentrations of $\mathrm{Fe}$ and $\mathrm{P}$ were examined by the modified molybdenum blue spectrometric method and the modified 1,10-phenanthroline spectrometric method, respectively. Furthermore, the phases of the slags after shaking experiments were also examined by XRD.

\section{Results and Discussion}

\section{Variation of $\mathrm{pH}$}

Figure 2 shows the variation of $\mathrm{pH}$ with time for seawater containing various concentrations of gluconic acid. For

Table 2 Chemical composition of artificial seawater

\begin{tabular}{ll}
\hline Constituent & Concentration $(\mathrm{mg} / \mathrm{L})$ \\
\hline $\mathrm{NaCl}$ & 24,534 \\
$\mathrm{MgCl}_{2} \cdot 6 \mathrm{H}_{2} \mathrm{O}$ & 11,112 \\
$\mathrm{Na}_{2} \mathrm{SO}_{4}$ & 4094 \\
$\mathrm{CaCl}_{2} \cdot 2 \mathrm{H}_{2} \mathrm{O}$ & 1535 \\
$\mathrm{KCl}$ & 695 \\
$\mathrm{NaHCO}$ & 201 \\
$\mathrm{KBr}$ & 101 \\
$\mathrm{SrCl}_{2} \cdot 6 \mathrm{H}_{2} \mathrm{O}$ & 43 \\
$\mathrm{H}_{3} \mathrm{BO}_{3}$ & 27 \\
$\mathrm{NaF}$ & 3 \\
\hline
\end{tabular}

both slags, $\mathrm{pH}$ increased dramatically in the beginning; however, for prolonged shaking time, the $\mathrm{pH}$ increase was only moderate for slag S-1 and stable around 10.1 for slag $\mathrm{S}-2$. As illustrated in our previous work [13], the buffering action provided by the dissociation of gluconic acid is negligible. In the case of slag $\mathrm{S}-1, \mathrm{pH}$ increased with increase of concentration of gluconic acid. The highest $\mathrm{pH}$ value was approximately 9.0 with $0.4 \mathrm{~g} / \mathrm{L}$ gluconic acid. In the case of slag $\mathrm{S}-2$, the variation of $\mathrm{pH}$ with the gluconic acid concentration was not obvious, whereas $\mathrm{pH}$ was slightly higher than that without addition of gluconic acid. The $\mathrm{pH}$ of solution with slag S-2 was much higher than that of slag S-1, which is the same as that in the previous work [13].

\section{Dissolution of $\mathrm{Ca}$ and Concentration Change of $\mathrm{Mg}$}

Figure 3 shows the dissolution behavior of $\mathrm{Ca}$ from slags S-1 and S-2 into seawater with various concentrations of gluconic acid. The concentration of $\mathrm{Ca}$ increased upon increasing both the shaking time and the concentration of gluconic acid, while it was much higher in the case of slag $\mathrm{S}-2$ than that of slag S-1. After $96 \mathrm{~h}$ shaking, the concentration of Ca changed from 394 to $417 \mathrm{mg} / \mathrm{L}$ for slag S-1 and from 604 to $828 \mathrm{mg} / \mathrm{L}$ for slag S-2. For slag S-1, the concentration of $\mathrm{Ca}$ in seawater with gluconic acid was larger than that without gluconic acid, while for those solutions with 0.25 and $0.50 \mathrm{~g} / \mathrm{L}$ gluconic acid were similar. Since the dissolved amount of Ca from slag S-1 was small, the dissolution behavior of $\mathrm{Ca}$ was largely influenced by other elements contained in seawater. In the case of slag S2 , the increment of $\mathrm{Ca}$ concentration was followed by the concentration of gluconic acid. The dissolution of $\mathrm{Ca}$ from slag into seawater is expressed by reaction (1) [14-16].

$\mathrm{CaO}$ (in slag) $+\mathrm{H}_{2} \mathrm{O} \rightleftharpoons \mathrm{Ca}^{2+}+2 \mathrm{OH}^{-}$

Dissolution of $\mathrm{CaO}$ is enhanced by the complexation reaction between $\mathrm{Ca}$ and gluconic acid such as reaction (2)
Fig. 2 Variation of $\mathrm{pH}$ with time for seawater containing various concentrations of gluconic acid. Gluconic acid $(\mathrm{g} /$ L): $\multimap-0, \neg-0.12, \neg-$ $0.25,-\square-0.50, \cdots \star$ Seawater
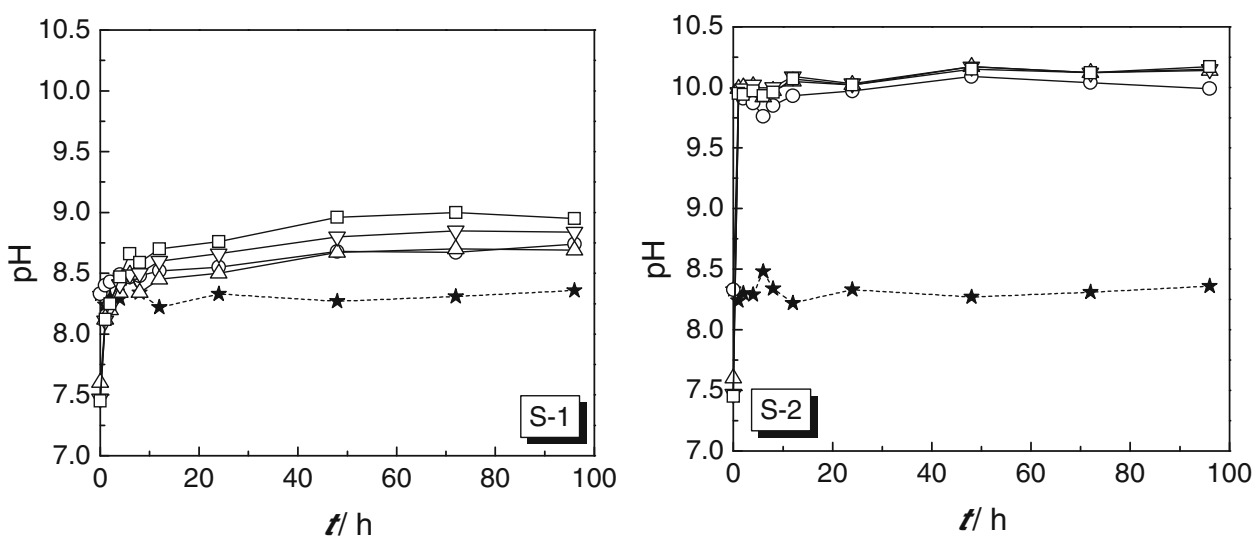
Fig. 3 Dissolution behaviors of Ca from slags S-1 and S-2 into seawater with various concentrations of gluconic acid. Gluconic acid $(\mathrm{g} / \mathrm{L}):-0$ : 0 , $\triangle 0.12, \neg-0.25, \multimap-$ $0.50, \ldots \star \cdots$ Seawater
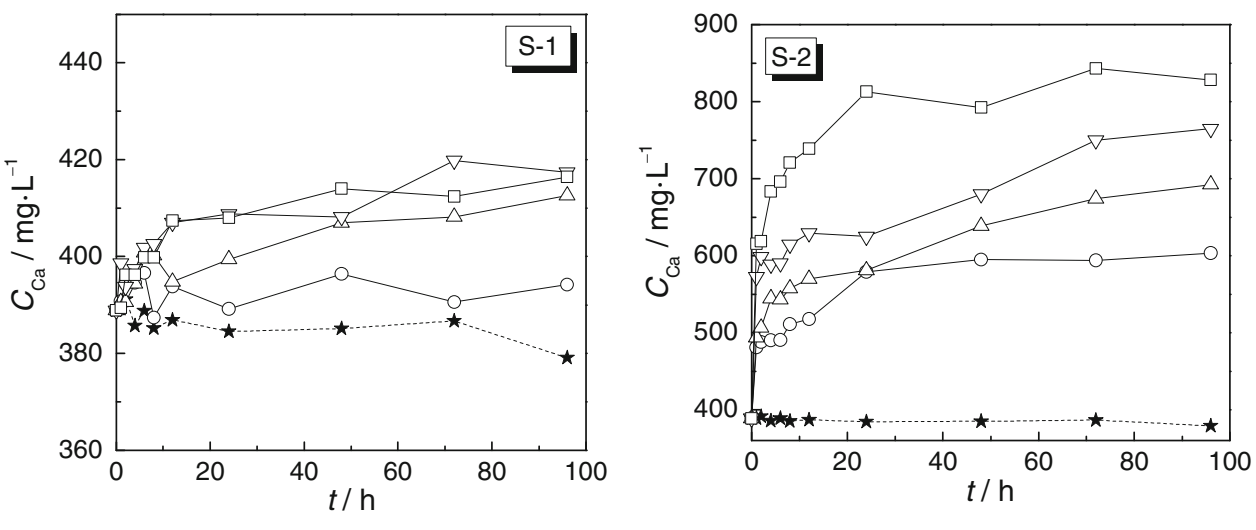

[17]. Hence, $\mathrm{pH}$ increased with increasing the concentration of gluconic acid for slag S-1.

$$
\mathrm{Ca}^{2+}+\mathrm{GH}_{4}^{-} \rightleftharpoons \mathrm{Ca}\left(\mathrm{GH}_{4}\right)^{+} \quad \log K_{2}=1.22(298 \mathrm{~K})[17]
$$

where $\mathrm{GH}_{4}{ }^{-}$is the symbolic form of gluconate ion.

Despite the significant dissolution of Ca from slag S-2 on adding gluconic acid, $\mathrm{pH}$ was still constant around 10.1, which is attributed to the precipitation of $\mathrm{Mg}^{2+}$ contained in the original artificial seawater. Figure 4 shows the concentration change of $\mathrm{Mg}$ in seawater during shaking of slags S-1 and S-2, with seawater containing various concentrations of gluconic acid.

With slag S-1, the concentration of $\mathrm{Mg}$ changed in a small range between 1172 and $1217 \mathrm{mg} / \mathrm{L}$, which is close to that of seawater. With slag S-2, the concentration of $\mathrm{Mg}$ decreased upon increasing both the shaking time and the concentration of gluconic acid. The smallest concentration of $\mathrm{Mg}$ was $918 \mathrm{mg} / \mathrm{L}$ after shaking for $96 \mathrm{~h}$ with $0.50 \mathrm{~g} / \mathrm{L}$ gluconic acid.

Magnesium hydroxide has relatively lower solubility compared to calcium hydroxide and thus $\mathrm{Mg}^{2+}$ in the seawater precipitates as $\mathrm{Mg}(\mathrm{OH})_{2}$ by the substitution reaction (3) when $\mathrm{pH}$ reaches a certain value [3, 14-16]. Hence, the concentration change of $\mathrm{Mg}$ shows an opposite trend to that of Ca for slag S-2.

$$
\mathrm{CaO} \text { (in slag) }+\mathrm{H}_{2} \mathrm{O}+\mathrm{Mg}^{2+} \rightleftharpoons \mathrm{Ca}^{2+}+\mathrm{Mg}(\mathrm{OH})_{2}(\mathrm{~s})
$$

Figure 5 shows the relationship between the concentrations of $\mathrm{Ca}$ and $\mathrm{Mg}$ during shaking of slags S-1 and S-2. In the case of slag S-1, shown in Fig. 5a, the concentration of $\mathrm{Mg}$ was not affected by the increase in the concentration of $\mathrm{Ca}$. In the case of slag S-2, shown in Fig. 5b, the concentration of $\mathrm{Mg}$ decreased linearly with increasing the concentration of $\mathrm{Ca}$, regardless of gluconic acid concentration. However, the slopes of the linear regression lines are different for the solutions with and without gluconic acid, which is due to the formation of magnesium-gluconate complex according to reaction (4) [17]. Since the soluble $\mathrm{Mg}$ concentration becomes higher, the slope of the linear regression line between $\mathrm{Ca}$ and $\mathrm{Mg}$ concentrations with gluconic acid is larger (less steep) compared to that without gluconic acid.

$\mathrm{Mg}^{2+}+\mathrm{GH}_{4}^{-} \rightleftharpoons \mathrm{Mg}\left(\mathrm{GH}_{4}\right)^{+} \quad \log K_{4}=0.70[17]$

The concentrations of $\mathrm{Ca}$ and $\mathrm{Mg}$ are shown in the solubility diagrams of $\mathrm{Ca}$ and $\mathrm{Mg}$ in Fig. 6 [3]. The concentrations of $\mathrm{Ca}$ and $\mathrm{Mg}$ for slag $\mathrm{S}-1$ are below the saturation line of $\mathrm{Mg}(\mathrm{OH})_{2}$. Therefore, $\mathrm{pH}$ increased slightly but the concentration of $\mathrm{Mg}$ did not change with the dissolution of $\mathrm{Ca}$. The concentrations of $\mathrm{Ca}$ and $\mathrm{Mg}$ for slag S-2 are located above the saturation line of $\mathrm{Mg}(\mathrm{OH})_{2}$; hence, the concentration of $\mathrm{Mg}$ decreased, and $\mathrm{pH}$ was maintained at approximately 10.1 during the dissolution of Ca.

\section{Dissolution of $\mathrm{Si}$}

The dissolution behavior of $\mathrm{Si}$ from slags into seawater containing gluconic acid is shown in Fig. 7. Depending on the $\mathrm{CaO} / \mathrm{SiO}_{2}$ ratio of slag, the dissolution behavior of $\mathrm{Si}$ was quite different. In the case of slag S-1 with the $\mathrm{CaO}$ / $\mathrm{SiO}_{2}$ ratio of 1 , the concentration of $\mathrm{Si}$ increased upon increasing both the shaking time and the concentration of gluconic acid. After $96 \mathrm{~h}$ shaking, the concentrations of $\mathrm{Si}$ were $5.13,10.58,15.80$, and $20.13 \mathrm{mg} / \mathrm{L}$ in seawater with $0,0.12,0.25$, and $0.50 \mathrm{~g} / \mathrm{L}$ gluconic acid, respectively. The concentration of Si monotonically increased with increasing the concentration of gluconic acid. In the case of slag $\mathrm{S}-2$ with the $\mathrm{CaO} / \mathrm{SiO}_{2}$ ratio of 2 , the concentration of $\mathrm{Si}$ reached a maximum at the beginning of shaking, and then it decreased abruptly toward stable values. In general, the concentration of Si increased with increasing the concentration of gluconic acid. In the case of seawater, the soluble $\mathrm{Si}$ concentration varied from 0 to $2.09 \mathrm{mg} / \mathrm{L}$. However, there is no $\mathrm{Si}$ element in the artificial seawater as shown in 
Fig. 4 Concentration change of $\mathrm{Mg}$ in seawater during shaking of slags S-1 and S-2 with seawater containing various concentrations of gluconic acid. Gluconic acid $(\mathrm{g} / \mathrm{L}):-0-0$, $\triangle-0.12, \square-0.25, \square-$ $0.50, \cdots \star-$ Seawater
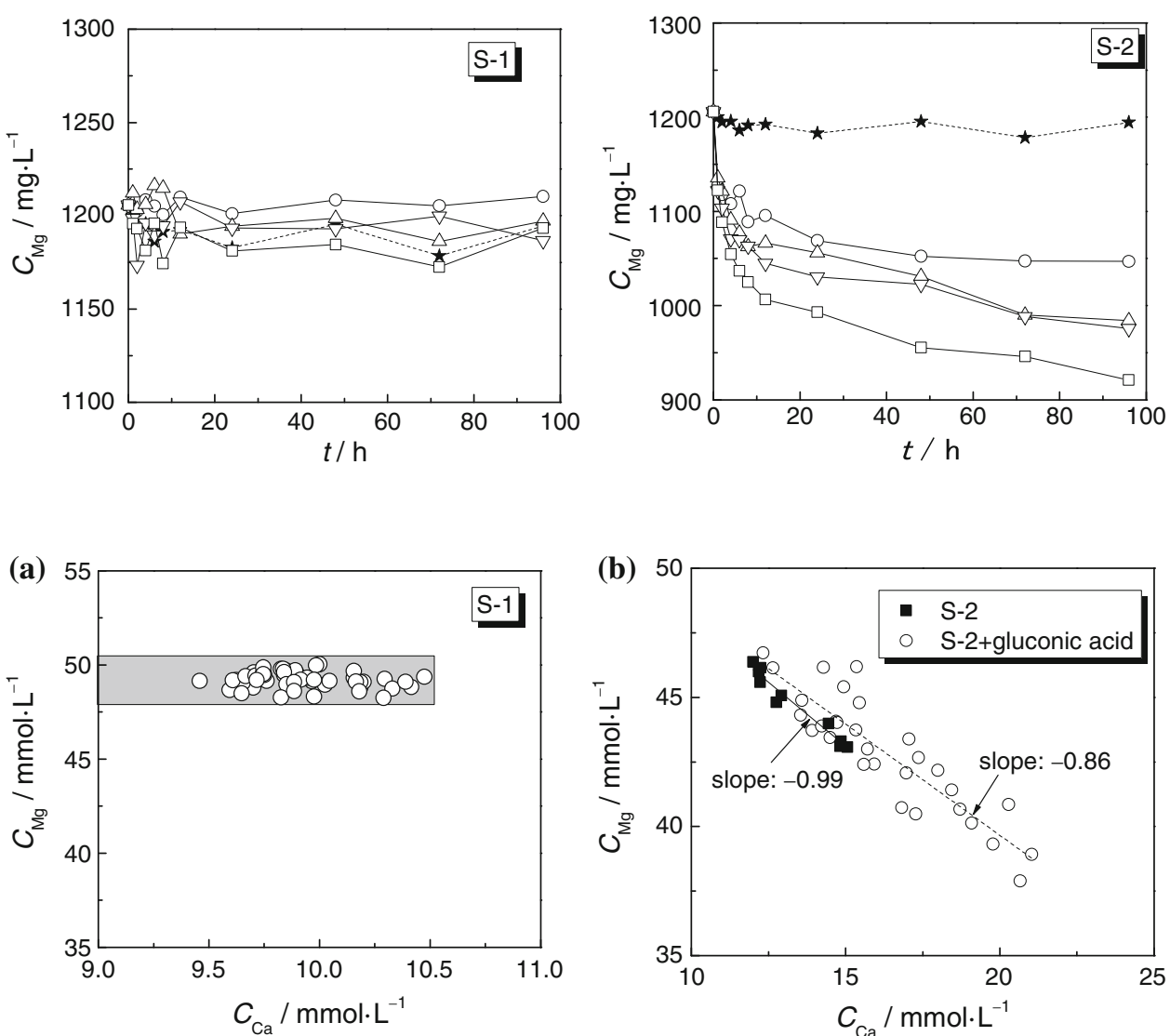

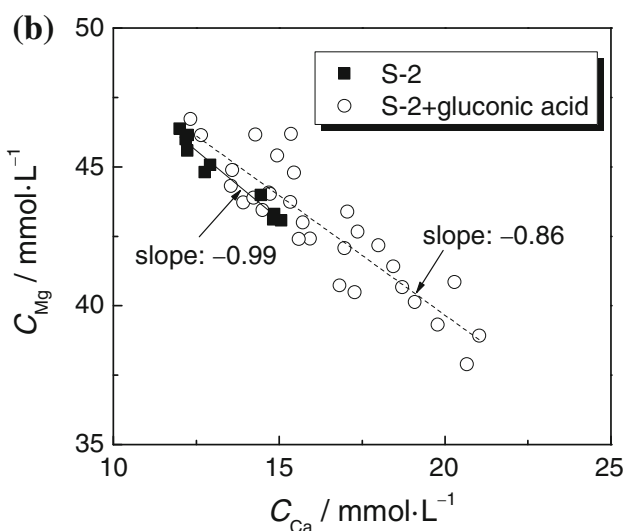

Fig. 5 Relationship between concentrations of $\mathrm{Ca}$ and $\mathrm{Mg}$ during shaking: a slag S-1; b slag S-2

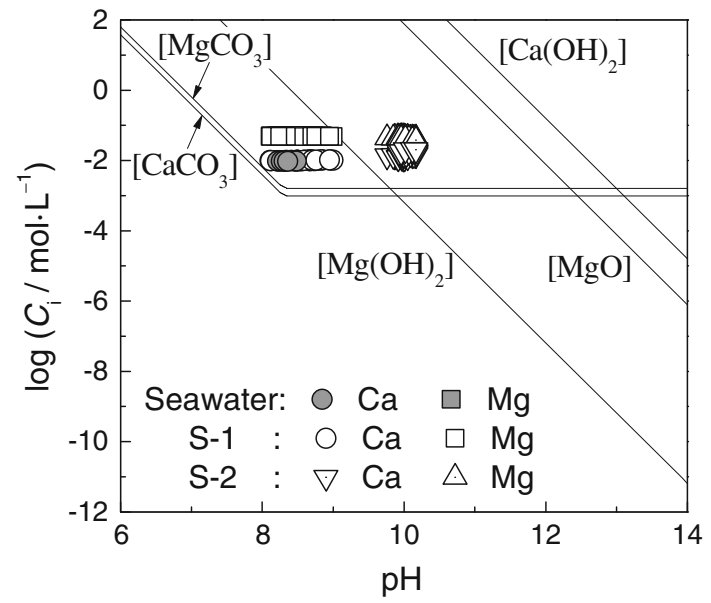

Fig. 6 Solubility diagram of $\mathrm{Ca}$ and $\mathrm{Mg}$ together with the shaking results adding gluconic acid, it is still equilibrated with silicon hydrates as shown in the diagram.

For slag $\mathrm{S}-2, \mathrm{Si}$ concentration is located in the region between $\mathrm{H}_{2} \mathrm{SiO}_{3}$ and $\mathrm{H}_{4} \mathrm{SiO}_{4}$ saturation lines, and its species is $\mathrm{HSiO}_{3}{ }^{-}$. Thus, the dissolution of $\mathrm{Si}$ from slag $\mathrm{S}-2$ into seawater can be deduced by reactions (5) and (6) [3, 4, 18]:

$$
\begin{aligned}
& 2 \mathrm{CaO} \cdot \mathrm{SiO}_{2}(\mathrm{~s})+3 \mathrm{H}_{2} \mathrm{O} \rightleftharpoons \mathrm{H}_{2} \mathrm{SiO}_{3}(\mathrm{~s})+2 \mathrm{Ca}^{2+}+4 \mathrm{OH}^{-} \\
& \log K_{5}=-26.6(298 \mathrm{~K})[4]
\end{aligned}
$$

$\mathrm{H}_{2} \mathrm{SiO}_{3}(\mathrm{~s}) \rightleftharpoons \mathrm{H}^{+}+\mathrm{HSiO}_{3}^{-} \quad \log K_{6}=-11.8(298 \mathrm{~K})[4]$

With the fast dissolution of $\mathrm{Ca}$ from slag S-2 into seawater, according to reaction (5), solid $\mathrm{H}_{2} \mathrm{SiO}_{3}$ is formed. Then the concentration of $\mathrm{Si}$ increases as the reactions (5) and (6) proceed. On the other hand, Ca ion is supplied by the dissolution of some other phases. Subsequently, another reaction (7) becomes significant when the reactions (5) and (6) reach a certain extent.

$$
\begin{aligned}
& \mathrm{HSiO}_{3}^{-}+2 \mathrm{Ca}^{2+}+3 \mathrm{OH}^{-} \rightleftharpoons 2 \mathrm{CaO} \cdot \mathrm{SiO}_{2}(\mathrm{~s})+2 \mathrm{H}_{2} \mathrm{O} \\
& \log K_{7}=24.5(298 \mathrm{~K})[4]
\end{aligned}
$$

When the reactions (5), (6), and (7) reach the steady state with the extension of the shaking time, the 
Fig. 7 Dissolution behaviors of Si from slags S-1 and S-2 with various concentrations of gluconic acid. Gluconic acid (g/ L): $\multimap-0, \neg-0.12, \neg-$ $0.25, \multimap-0.50, \cdots \star$ Seawater
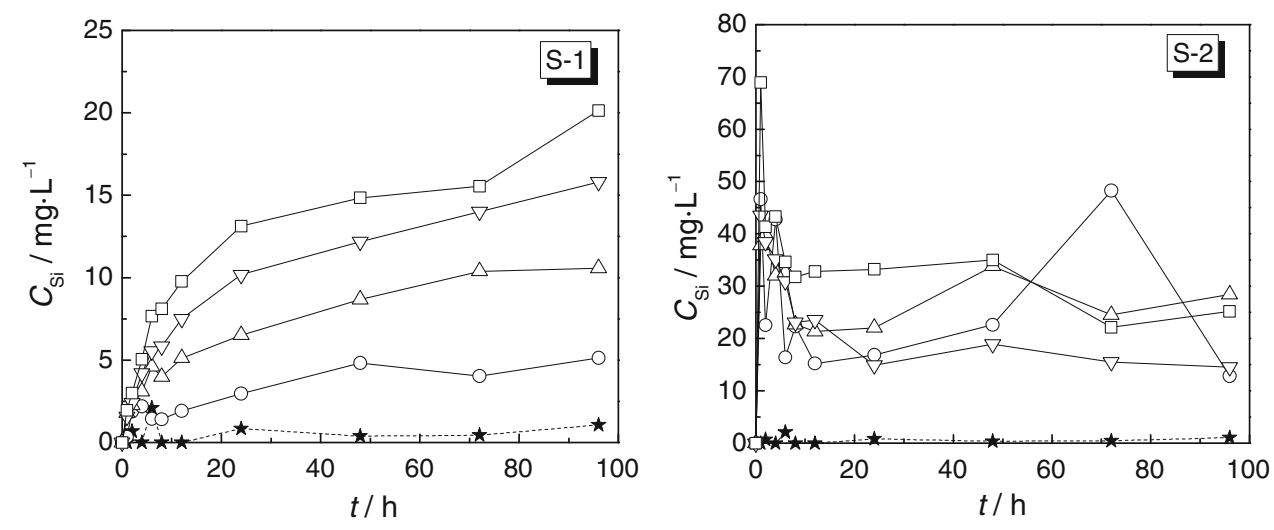

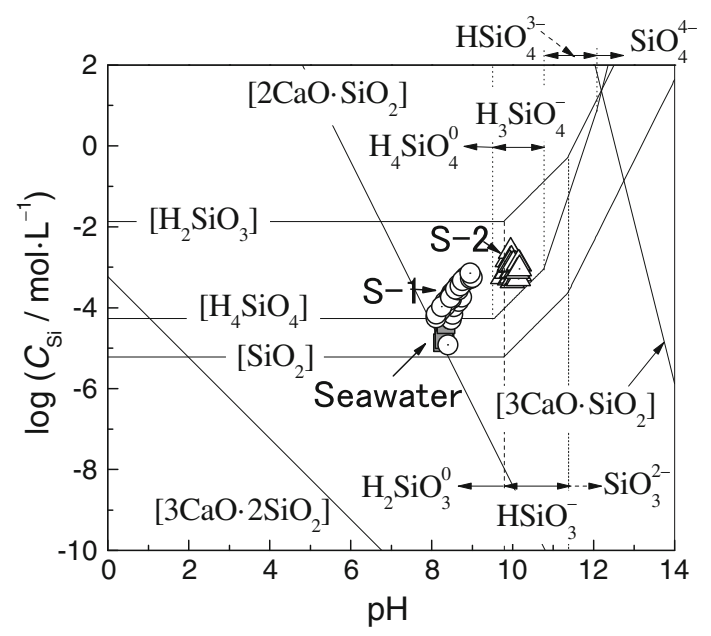

Fig. 8 Solubility diagram of Si together with the shaking results

concentration of Si becomes stable. Furthermore, due to the complexation reaction between $\mathrm{Ca}$ and gluconic acid, gluconic acid helps the reaction (5) proceed forward; hence, the concentration of $\mathrm{Si}$ increases with increasing the concentration of gluconic acid.

For slag S-1, the Si concentration is also located in the region between $\mathrm{H}_{2} \mathrm{SiO}_{3}$ and $\mathrm{H}_{4} \mathrm{SiO}_{4}$ phases, while $\mathrm{Si}$ mainly exists as $\mathrm{H}_{2} \mathrm{SiO}_{3}^{0}$. The dissolution of $\mathrm{Si}$ from slag S-1 into seawater is expected to be similar to that from slag $\mathrm{S}-2$, which is the initial formation of silicon hydrate followed by the gradual dissolution into seawater. However, the reaction (7) is not taking place for slag S-1 because of the lower concentration of $\mathrm{Ca}$, and thus, the concentration of Si monotonously increases with increasing shaking time.

Moreover, the enhancement of the dissolution of Si by gluconic acid can be attributed to the formation of silicon hydrate. Since gluconic acid is a weak polybasic acid, it is easier to give $\mathrm{H}^{+}$to the solid silica than water [reaction (5)] at the alkaline environment. Therefore, the larger concentration of gluconic acid is more favorable to form silicon hydrate which has larger solubility. Under the present shaking conditions, the chelate between silicon and gluconic acid is expected not to form because both of them exist as anions.

Dissolution of $\mathrm{P}$

The dissolution behavior of $\mathrm{P}$ from slags into seawater with various concentrations of gluconic acid is shown in Fig. 9. The dissolution behavior of $\mathrm{P}$ greatly depended on the $\mathrm{CaO} / \mathrm{SiO}_{2}$ ratio of slag. In the case of slag $\mathrm{S}-1$, the concentration of $\mathrm{P}$ increased upon increasing both the shaking time and the concentration of gluconic acid. After $96 \mathrm{~h}$ shaking, the concentrations of $\mathrm{P}$ were $0.460,1.358,1.854$, and $2.289 \mathrm{mg} / \mathrm{L}$ in seawater with $0,0.12,0.25$, and $0.50 \mathrm{~g} /$ $\mathrm{L}$ gluconic acid, respectively. In the case of slag $\mathrm{S}-2$, the soluble $\mathrm{P}$ was not detected in seawater without gluconic acid. The maximum concentration appeared in the beginning, and then $\mathrm{P}$ concentration decreased dramatically in the initial shaking period or even dropped below the detection limit. Comparing the dissolution behaviors of $\mathrm{P}$ from slags $\mathrm{S}-1$ and $\mathrm{S}-2$, the $\mathrm{P}$ concentration from slag $\mathrm{S}-2$ is much lower than that from slag $\mathrm{S}-1$, which reveals that slags with larger $\mathrm{CaO} / \mathrm{SiO}_{2}$ ratio effectively hinder the dissolution of $\mathrm{P}$.

Figure 10 shows the solubility diagram of $\mathrm{P}$ together with the concentration of $\mathrm{P}$ dissolved from slags $\mathrm{S}-1$ and $\mathrm{S}-2$. The entire $\mathrm{P}$ concentration is located in the region between $2 \mathrm{CaO} \cdot \mathrm{P}_{2} \mathrm{O}_{5}$ and $\mathrm{Ca}_{3}\left(\mathrm{PO}_{4}\right)_{2}$ saturation lines, and the soluble species is $\mathrm{HPO}_{4}{ }^{2-}$. Thus, the dissolution of $\mathrm{P}$ can be expressed as reaction (8) [3].

For slag S-1, the chelation on the soluble $\mathrm{Ca}^{2+}$ is provided by gluconic acid, which makes reaction (8) proceed forward. Hence, the concentration of $\mathrm{P}$ becomes larger with larger concentration of gluconic acid.

$$
\begin{aligned}
& 2 \mathrm{CaO} \cdot \mathrm{P}_{2} \mathrm{O}_{5}(\mathrm{~s})+\mathrm{H}_{2} \mathrm{O} \rightleftharpoons 2 \mathrm{HPO}_{4}^{2-}+2 \mathrm{Ca}^{2+} \\
& \log K_{8}=-12.1(298 \mathrm{~K})[4]
\end{aligned}
$$

For slag S-2, reaction (9) takes place simultaneously to control the concentration of $\mathrm{P}$. 
Fig. 9 Dissolution behaviors of $P$ from slags S-1 and S-2 with various concentrations of gluconic acid. Gluconic acid $(\mathrm{g} /$ $\mathrm{L}): \multimap 0, \triangle \triangle 0.12,-\nabla-$ $0.25, \rightarrow \square-0.50, \cdots \star$ Seawater
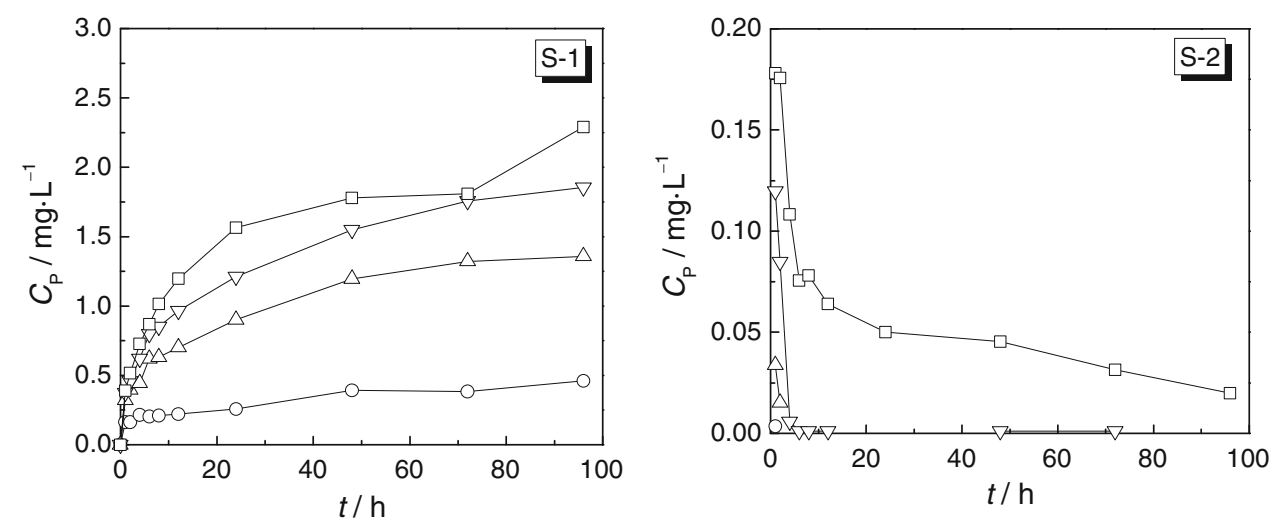

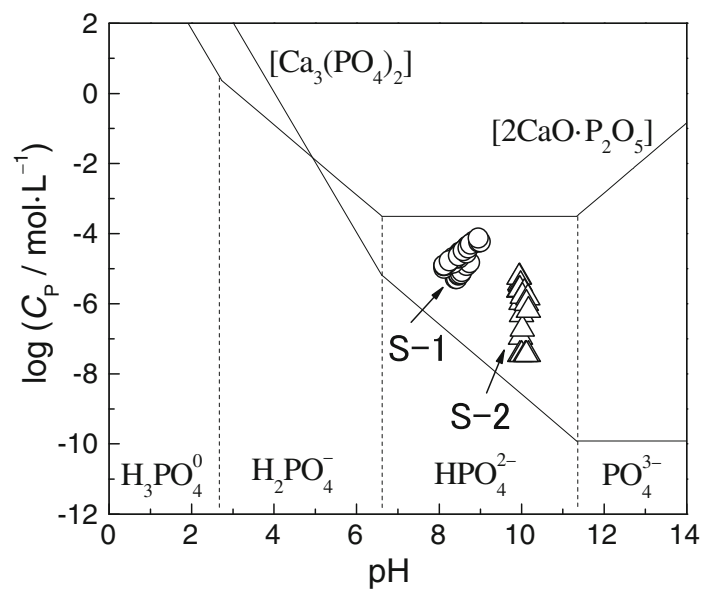

Fig. 10 Solubility diagram of $P$ together with the shaking results

$$
\begin{aligned}
& 3 \mathrm{CaO} \cdot \mathrm{P}_{2} \mathrm{O}_{5}(\mathrm{~s})+2 \mathrm{H}_{2} \mathrm{O} \rightleftharpoons 2 \mathrm{HPO}_{4}^{2-}+3 \mathrm{Ca}^{2+}+2 \mathrm{OH}^{-} \\
& \log K_{9}=-34.6(298 \mathrm{~K})[4]
\end{aligned}
$$

Reaction (9) proceeds backward when the concentration of Ca dissolved from slag S-2 increases dramatically (despite the chelation of soluble $\mathrm{Ca}^{2+}$ provided by gluconic acid), which subsequently results in the decrease of the $\mathrm{P}$ concentration in seawater. Therefore, the concentration of $\mathrm{P}$ decreases with increasing the shaking time.

\section{Dissolution of $\mathrm{Fe}$}

The dissolution behavior of Fe from slags into seawater with various concentrations of gluconic acid is shown in Fig. 11. The soluble Fe was not detected in the seawater without gluconic acid for both slags $\mathrm{S}-1$ and $\mathrm{S}-2$. The $\mathrm{CaO} /$ $\mathrm{SiO}_{2}$ ratio of slag determines the dissolution behaviors of $\mathrm{Fe}$ from slags into seawater. In the case of slag S-1, the dissolution of $\mathrm{Fe}$ increased with increasing the shaking time as well as concentration of gluconic acid. After $96 \mathrm{~h}$ shaking, the concentrations of Fe were 12.12, 18.72, and $24.74 \mathrm{mg} / \mathrm{L}$ in seawater with $0.12,0.25$, and $0.50 \mathrm{~g} / \mathrm{L}$ gluconic acid, respectively. In the case of slag $\mathrm{S}-2$, the concentration of Fe decreased quickly before $12 \mathrm{~h}$ and then further decreased gradually with shaking time. After $96 \mathrm{~h}$ shaking, the concentrations of $\mathrm{Fe}$ were $0.01,0.33$, and $1.28 \mathrm{mg} / \mathrm{L}$ with $0.12,0.25$, and $0.50 \mathrm{~g} / \mathrm{L}$ gluconic acid, respectively.

The variations of the ORP during the shaking of slags S-1 and S-2 with seawater containing various concentrations of gluconic acid are shown in Fig. 12. The ORP fluctuated in the initial shaking period and this phenomenon was smaller for shaking with slags compared to shaking of seawater. At the same time, the ORP in the case of shaking with slag S-2 was much smaller than that with slag S-1. Increasing the concentration of gluconic acid decreased the ORP.

The potential-pH diagram of iron-water system at 298.15 K with $10^{-6} \mathrm{~mol} / \mathrm{L}$ soluble iron is shown in Fig. 13 [3] together with the measured ORP. The ORP of the shaking solution is located in the stable region of $\mathrm{Fe}_{2} \mathrm{O}_{3}$ phase, which implies that the concentration of soluble $\mathrm{Fe}$ is extremely low. However, the measured soluble Fe concentration in seawater with gluconic acid is much higher than that predicted by the potential-pH diagram of ironwater system.

Figure 14 [11] shows the solubility diagram of Fe with the shaking results. Soluble Fe during shaking of slag S-1 is in equilibrium with $\mathrm{FeO}$ and $\mathrm{Fe}(\mathrm{OH})_{2}$ phases but larger than the equilibrium values. The soluble Fe species is considered to be $\mathrm{Fe}^{2+}$. On the contrary, the soluble $\mathrm{Fe}$ during shaking of slag $\mathrm{S}-2$ is higher than the equilibrium value for $\mathrm{Fe}(\mathrm{OH})_{3}$ and the soluble Fe species would be $\mathrm{Fe}(\mathrm{OH})_{4}^{-}$. This excess portion is attributed to the formation of iron-gluconate complexes.

For slag S-1, ferrous ion and gluconate ion form complex as reaction (10) suggests [20]. 
Fig. 11 Dissolution behaviors of Fe from slags S-1 and S-2 with various concentrations of gluconic acid
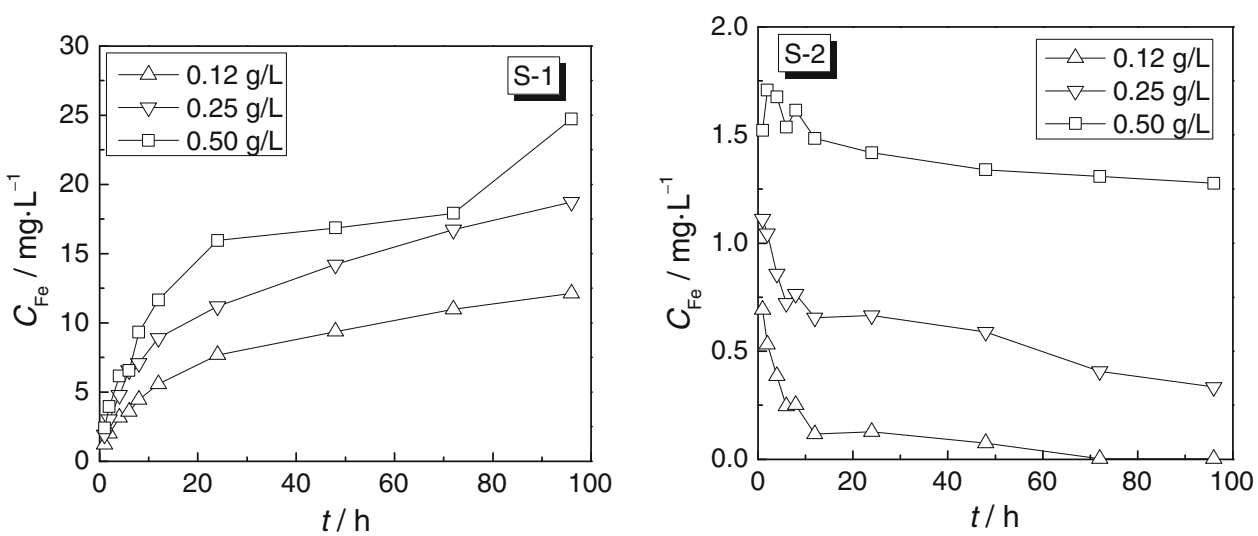

Fig. 12 Variation of ORP during the shaking of slags S-1 and S-2 with seawater containing various concentrations of gluconic acid. Gluconic acid $(\mathrm{g} / \mathrm{L}):-0-0$, $\neg-0.12, \square-0.25, \square-$ $0.50, \cdots \star-$ Seawater
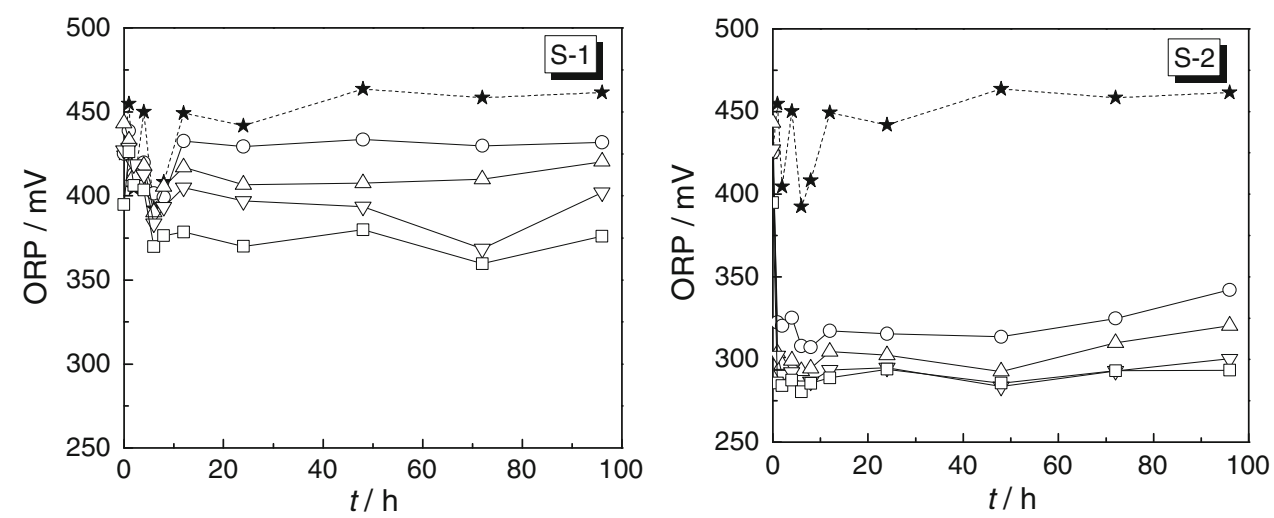

$\mathrm{Fe}-\mathrm{H}_{2} \mathrm{O}, 298.15 \mathrm{~K}$

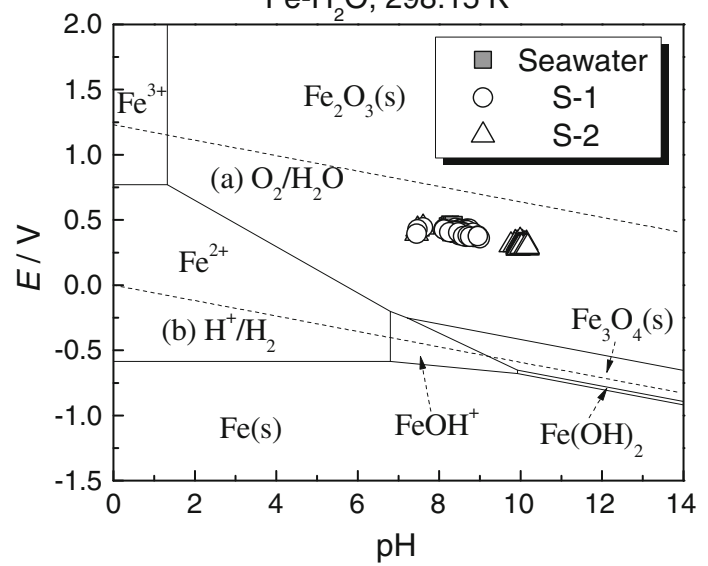

Fig. 13 Potential-pH diagram of iron-water system with the shaking results

$$
\mathrm{Fe}^{2+}+\mathrm{GH}_{4}^{-} \rightleftharpoons \mathrm{Fe}\left(\mathrm{GH}_{4}\right)^{+} \log K_{10}=1.0(298 \mathrm{~K})[20]
$$

For slag S-2, ferric ion and gluconate ion form a series of complexes with the increase of $\mathrm{pH}$ according to the following reactions (11-14) [17, 19-21]:

$$
\begin{aligned}
& \mathrm{Fe}^{3+}+\mathrm{GH}_{4}^{-} \rightleftharpoons \mathrm{Fe}\left(\mathrm{GH}_{4}\right)^{2+} \\
& \log K_{11}=17.1(298 \mathrm{~K})[17,20]
\end{aligned}
$$

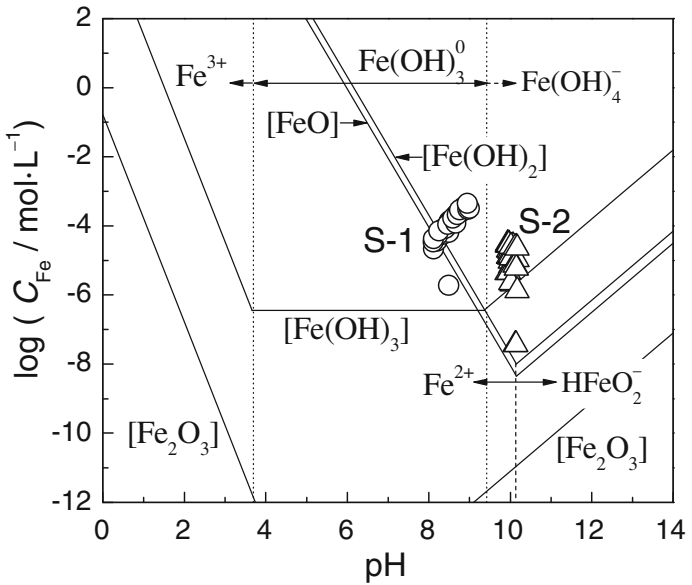

Fig. 14 Solubility diagram of Fe with the shaking results

$$
\begin{aligned}
& \mathrm{Fe}\left(\mathrm{GH}_{4}\right)^{2+} \rightleftharpoons \mathrm{HFe}(\mathrm{GH})+2 \mathrm{H}^{+} \\
& \log K_{12}=-4.6(298 \mathrm{~K})[20]
\end{aligned}
$$

$\mathrm{HFe}(\mathrm{GH}) \rightleftharpoons \mathrm{Fe}(\mathrm{GH})^{-}+\mathrm{H}^{+} \quad \log K_{13}=-4.0(298 \mathrm{~K})[20]$

$\mathrm{Fe}(\mathrm{GH})^{-}+\mathrm{OH}^{-} \rightleftharpoons \mathrm{Fe}(\mathrm{GH})(\mathrm{OH})^{2-}$

$\log K_{14}=-13.3(298 \mathrm{~K})[20]$ 


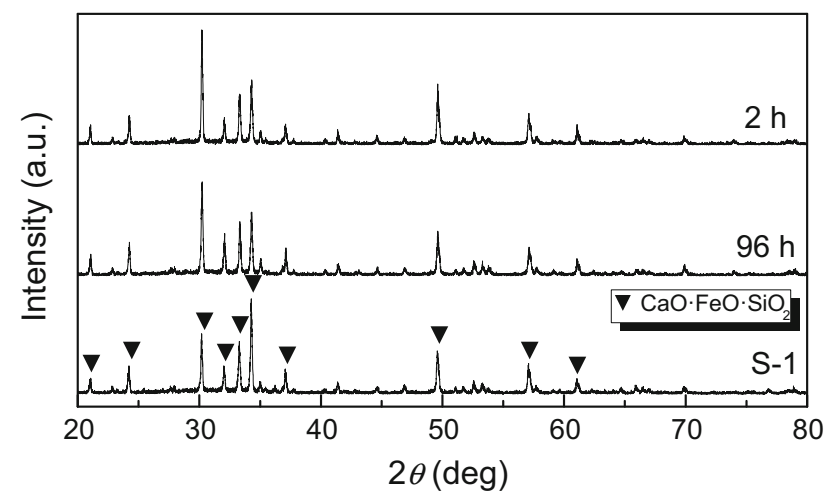

Fig. 15 XRD patterns of slag S-1 before and after shaking experiments

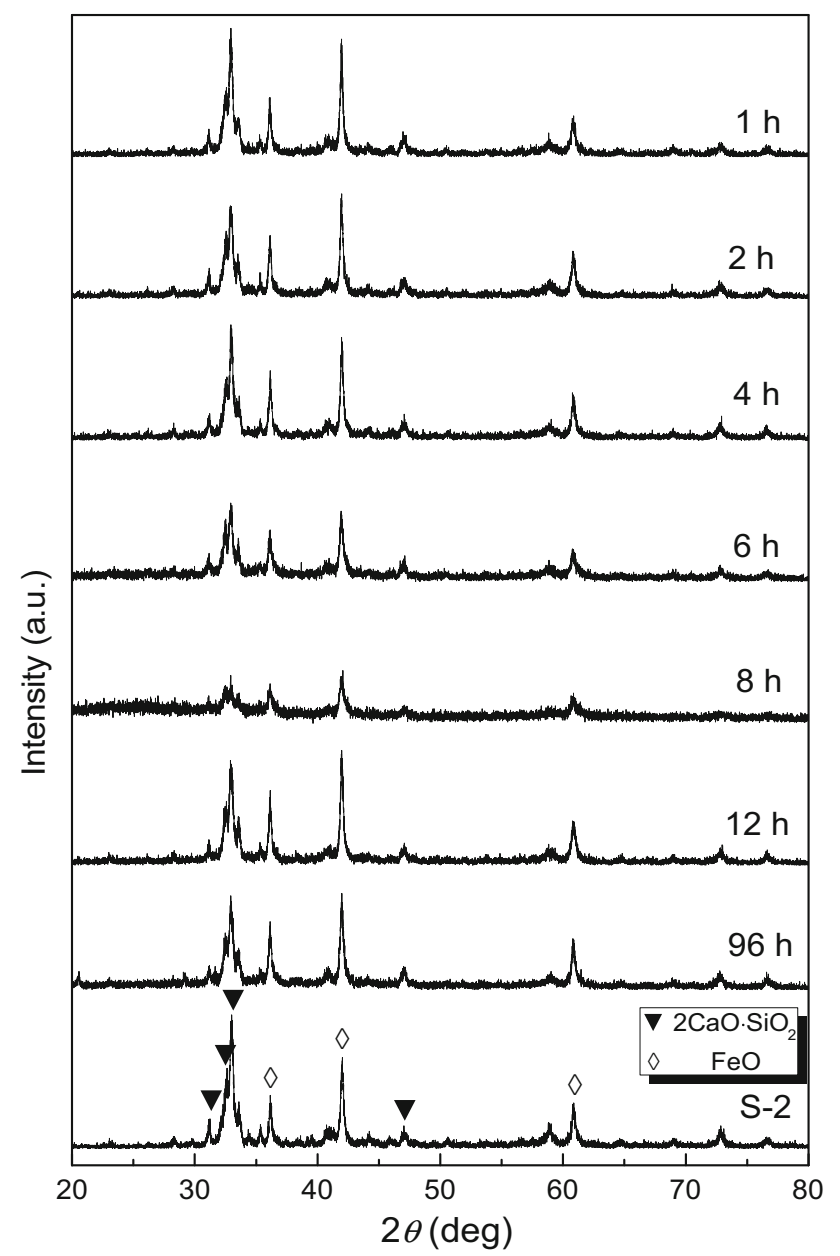

Fig. 16 XRD patterns of slag S-2 before and after shaking experiments

At higher $\mathrm{pH}$ regime, $\mathrm{Fe}^{3+}$ hardly exists, and it is prone to turn into $\mathrm{Fe}(\mathrm{GH})^{-}$and $\mathrm{Fe}(\mathrm{GH})(\mathrm{OH})^{2-}$ anions, and thus the concentration of Fe with slag S-2 is smaller than that with slag S-1. On the other hand, the equilibrium constants of ferric-gluconate complexation reactions (11-14) decrease with increasing $\mathrm{pH}$, which is another reason for the gradual decrease of soluble $\mathrm{Fe}$ with increase in shaking time. In addition, the ferric-gluconate complex is photoactive at large $\mathrm{pH}$ condition. Therefore, the gradual decrease in the concentration of $\mathrm{Fe}$ with time is due to the rapid photodegradation of the complex [22].

\section{XRD Analysis of Steelmaking Slags}

The XRD patterns of slags S-1 and S-2 before and after shaking experiments are shown in Figs. 15 and 16, respectively. The main peak positions in the diffraction patterns of the slags after shaking experiments are the same as those before shaking, which suggests that the main phases of slags do not change. Therefore, $\mathrm{CaO} \cdot \mathrm{FeO} \cdot \mathrm{SiO}_{2}$ phase and $2 \mathrm{CaO} \cdot \mathrm{SiO}_{2}$ and $\mathrm{FeO}$ phases mostly affect the dissolution behaviors of elements from slags S-1 and S-2, respectively.

\section{Conclusions}

The enhancement effect of gluconic acid on the dissolution of steelmaking slag into seawater was investigated by shaking experiments of slag and seawater with various shaking times and gluconic acid concentrations.

Because of the $\mathrm{Ca}$-gluconate complex, $\mathrm{pH}$ for shaking slag S-1 increased upon increasing both the shaking time and the concentration of gluconic acid. On the contrary, $\mathrm{pH}$ for shaking slag S-2 was constant around 10.1 independent of the concentration of gluconic acid, which is due to the simultaneous buffering action of $\mathrm{Mg}^{2+}$ contained in the original seawater.

Dissolutions of $\mathrm{Ca}, \mathrm{Si}, \mathrm{P}$, and $\mathrm{Fe}$ were enhanced by the addition of gluconic acid, but they largely depended on the $\mathrm{CaO} / \mathrm{SiO}_{2}$ ratio of slag. In the case of slag S-1 with the $\mathrm{CaO} / \mathrm{SiO}_{2}$ ratio of 1 , the concentrations of $\mathrm{Ca}, \mathrm{Si}, \mathrm{P}$, and $\mathrm{Fe}$ increased upon increasing both the shaking time and the concentration of gluconic acid. In the case of slag S-2 with the $\mathrm{CaO} / \mathrm{SiO}_{2}$ ratio of 2 , the concentration of $\mathrm{Ca}$ increased upon increasing both the shaking time and the concentration of gluconic acid, while those of $\mathrm{Si}, \mathrm{P}$, and $\mathrm{Fe}$ decreased upon increasing the shaking time or decreasing the concentration of gluconic acid. The enhancement effect of gluconic acid on the dissolution of $\mathrm{Si}$ is due to the formation of silica hydrate having larger solubility; that on the dissolution of $\mathrm{P}$ is due to the masking action of $\mathrm{Ca}$, which is beneficial to the existence of soluble $\mathrm{P}$; and that on the dissolution of $\mathrm{Fe}$ is attributed to the formation of irongluconate complexes. 


\section{References}

1. Nakamura Y, Taniguchi A, Okada S, Tokuda M (1998) Positive growth of phytoplankton under conditions enriched with steelmaking slag solution. ISIJ Int 38:390-398

2. Futatsuka T, Shitogiden K, Miki T, Nagasaka T, Hino M (2003) Dissolution behavior of elements in steelmaking slag into artificial seawater. Tetsu-to-Hagané 89(4):382-387

3. Zhang X, Matsuura H, Tsukihashi F (2012) Dissolution mechanism of various elements into seawater for recycling of steelmaking slag. ISIJ Int 52(5):928-933

4. Futatsuka T, Shitogiden K, Miki T, Nagasaka T, Hino M (2004) Dissolution behavior of nutrition elements from steelmaking slag into seawater. ISIJ Int 44:753-761

5. Arita K, Umiguchi Y, Taniguchi A (2003) Availability of steelmaking slag as a source of essential elements for phytoplankton. Tetsu-to-Hagané 89(4):415-421

6. Sugie K, Taniguchi A (2007) Bioavailability and dulability of the iron released from a steelmaking slag for tow Thalassiosira species. Tetsu-to-Hagané 93(8):558-564

7. Sugie K, Taniguchi A (2008) Continuation of bioavailability as an iron fertilizer of a steelmaking slag for two Thalassiosira species. Tetsu-to-Hagané 94(11):569-574

8. Kuma K, Nakabayashi S, Matsunaga K (1995) Photoreduction of $\mathrm{Fe}(\mathrm{III})$ by hydroxycarboxylic acids in seawater. Water Res 29(6):1559-1569

9. Baker AR, Croot PL (2010) Atmospheric and marine controls on aerosol iron solubility in seawater. Mar Chem 120(1-4):4-13

10. Nakabayashi S, Kudo I, Kuma K, Matsunaga K (1993) Trace determination of sugar acids (gluconic acid) in sea water by liquid chromatography. Anal Chim Acta 271(1):25-29

11. Kuma K, Nakabayashi S, Suzuki Y, Kudo I, Matsunaga K (1992) Photo-reduction of $\mathrm{Fe}(\mathrm{III})$ by dissolved organic substances and existence of $\mathrm{Fe}$ (II) in seawater during spring blooms. Mar Chem $37(1-2): 15-27$
12. Osborn EF, Arnulf M (1960) Revised and redrawn Phase equilibrium diagrams of oxide systems, Plate 7. American Ceramic Society and the Edward Orton, Jr., Ceramic Foundation

13. Zhang X, Atsumi H, Matsuura $H$, Tsukihashi $F$ (2014) Influence of gluconic acid on dissolution of $\mathrm{Si}, \mathrm{P}$ and $\mathrm{Fe}$ from steelmaking slag with different composition into seawater. ISIJ Int 54(6): 1443-1449

14. Miki T, Shitogiden K, Samada Y, Nagasaka T, Hino M (2003) Consideration of dissolution behavior of elements in steelmaking slag based on their stability diagram in seawater. Tetsu-to-Hagané 89(4):388-392

15. Miki T, Futatsuka T, Shitogiden K, Nagasaka T, Hino M (2004) Dissolution behavior of environmentally regulated elements from steelmaking slag into seawater. ISIJ Int 44(4):762-769

16. Yamamoto T, Suzuki M, Oh SJ, Matsuda O (2003) Release of phosphorus and silicon from steelmaking slag and their effects on growth of natural phytoplankton assemblages. Tetsu-to-Hagané 89(4):482-488

17. Sawyer DT (1964) Metal-gluconate complexes. Chem Rev 64(6):633-643

18. Yokoyama S, Suzuki A, Izaki M, Umemoto M (2009) Elution behavior of electronic arc furnace oxidizing slag into fresh water. Tetsu-to-Hagané 95(5):434-443

19. Mehltretter CL, Alexander BH, Rist CE (1953) Sequestration by sugar acids. Ind Eng Chem 45(12):2782-2784

20. Pecsok RL, Sandera J (1955) The gluconate complexes. II. The ferric-gluconate system. J Am Chem Soc 77(6):1489-1494

21. Prescott FJ, Shaw JK, Bilello JP, Cragwall GO (1953) Gluconic acid and its derivatives. Ind Eng Chem 45(2):338-342

22. Rose AL, Waite TD (2002) Kinetic model for Fe(II) oxidation in seawater in the absence and presence of natural organic matter. Environ Sci Technol 36(3):433-444 